\title{
Laporan kasus berbasis bukti Perbandingan Keamanan Aminofilin dan Kafein pada Bayi Prematur dengan Apne Prematuritas
}

Dian Artanti, Rinawati Rohsiswatmo, Rosalina

Departemen Ilmu Kesehatan Anak Fakultas Kedokteran Universitas Indonesia/RSCM, Jakarta

Latar belakang. Apne berulang sering terjadi pada bayi prematur. Kejadian ini dapat menimbulkan hipoksemia dan bradikardi , bila keadaannya semakin memburuk maka membutuhkan resusitasi dengan ventilasi tekanan positif. Obat golongan metilxantin (kafein dan teofilin) telah digunakan untuk mencegah apne.

Tujuan. Untuk mengetahui efek dan keamanan kafein dibandingkan teofilin pada bayi preamtur dengan periodik apne.

Metode. Penelusuran pustaka database elektronik : Pubmed, Cochrane, dan Highwire

Hasil. Hasil telaah sistematis menunjukkan kejadian takikardia dan intoleransi minum lebih sedikit pada kelompok kafein dengan Relative Risk (RR) 0,17; 95 \% Interval kepercayaan (IK) 0,04, 0,72; risk difference (RD) -0,29; 95\%IK: -0,47-0,10. Studi klinis acak mendapatkan Tidak ada hubungan bermakna antara dosis pemberian kafein dan aminofilin pada konsentrasi plasma keduanya, kecuali pada kelompok kafein pada hari tertentu.

Kesimpulan. Aminofilin dan kafein memiliki efektivitas yang sama dalam mengatasi apne pada bayi prematur. Efek toksisitas kafein lebih rendah dibandingkan aminofilin. Sari Pediatri 2017;19(2):108-13

Kata kunci: bayi prematur, apne, kafein, teofilin

\section{Comparison of Safety Aminophylline and Caffeine in Premature Babies with Prematurity Apne}

Dian Artanti, Rinawati Rohsiswatmo, Rosalina

Background. Recurrent apnea is common in preterm infants, particularly at very early gestational ages. These episodes of loss of effective breathing can lead to hypoxemia and bradycardia, which may be severe enough to require resuscitation including use of positive pressure ventilation. Two forms of methylxanthine (caffeine and theophylline) have been used to stimulate breathing in order to prevent apnea and its consequences.

Objective. To evaluate the effect of caffeine compared with theophylline treatment on the risk of apnea in preterm infants with recurrent apnea

Methods. Literature search using electronic data base: Pubmed, Cochrane, and Highwire.

Results. Sistematic review showed that tachycardia and feed intolerance were less in babies with caffeine wirh Relative Risk (RR) 0,17; 95\%CI: 0,04, 0,72; risk difference (RD) -0,29; 95\%CI: -0,47-0,10. RCT showed no correlation between caffeine and aminophylline dose to plasma concentration, except in the caffeine group at certain day.

Conclusion. Aminophyllin showed an effectiveness as caffeine for treating apnea in preterm infant. The effect of caffeine toxicity is lower than that of aminophylline. Sari Pediatri 2017;19(2):108-13

Key words: preterm baby, apnea, caffeine, theophylline

Alamat korespondensi: Dr. Dian Artanti. Departemen Ilmu Kesehatan Anak Fakultas Kedokteran Universitas Indonesia/RSCM, Jakarta. Email: dr.dianartanti@yahoo.co.id 
Dian Artanti dkk: Perbandingan keamanan aminofilin dan kafein pada bayi prematur dengan apne prematuritas

A pne pada neonatus didefinisikan sebagai pola napas abnormal dengan episode henti napas selama lebih dari 20 detik atau kurang dari 10 detik, disertai desaturasi atau bradikardia. Apne merupakan salah satu komplikasi tersering pada bayi prematur dengan prevalens mencapai $25-50 \%$ dan kejadiannya meningkat seiring dengan berkurangnya usia gestasi. ${ }^{1}$ Apnea of prematurity (AOP) terjadi pada lebih dari $50 \%$ bayi dengan berat lahir $<1500 \mathrm{~g}$ dan $80 \%$ pada bayi dengan berat lahir $<1000$ g. ${ }^{2}$ Beberapa teori penyebab apne dihubungkan dengan tipe apne, antara lain, tipe sentral, tipe obstruktif, dan tipe campuran. ${ }^{3}$

Patofisiologi AOP dihubungkan dengan imaturitas batang otak sebagai pusat pernapasan. Bayi prematur membutuhkan waktu konduksi batang otak yang lebih lama pada saat serangan apne dibandingkan dengan bayi cukup bulan. ${ }^{3}$ Diagnosis AOP ditegakkan bila kondisi lain sebagai kemungkinan penyebab apne seperti infeksi, gangguan metabolik dan kelainan jantung dapat disingkirkan. ${ }^{1}$

Apne pada bayi prematur akan membaik dengan bertambahnya usia bayi. Terapi farmakologis pada umumnya digunakan untuk menurunkan frekuensi apne, serta mengurangi kejadian hipoksia dan bradikardia. ${ }^{1}$ Penggunaan metilxantin, antara lain, aminofilin, teofilin dan kafein, telah diteliti sejak tahun 70 -an. Teofilin dan kafein merupakan obat yang paling sering diberikan pada perawatan intensif. Golongan metilxantin bekerja menstimulasi susunan saraf pusat, terbukti meningkatkan usaha napas, menurunkan ambang sensitif untuk hiperkapni, dan meningkatkan kontraktilitas diafragma. Golongan ini merupakan antagonis reseptor adenosin non-spesifik. ${ }^{2}$

Obat-obat yang termasuk golongan metilxantin mempunyai efek terapeutik yang sebanding. Aminofilin sebagai terapi AOP sudah mulai digantikan dengan kafein karena indeks terapeutik kafein yang lebih luas. Efek samping metilxantin, yaitu takikardia, takipneu, jitteriness, tremor, iritabel, muntah, instabilitas gula darah, dan intoleransi minum. ${ }^{4,5}$ Penggunaan aminofilin sendiri masih banyak digunakan di unit Perinatologi Rumah Sakit sebagai terapi pilihan dan tidak tersedianya kafein dalam bentuk intravena. Penelitian berbasis bukti ini ditujukan untuk membahas keamanan penggunaan aminofilin dibandingkan dengan kafein sebagai terapi pada AOP.

\section{Kasus}

Seorang bayi laki-laki usia gestasi 32 minggu berat lahir 1275 gram, lahir secara bedah kaisar emergensi atas indikasi ibu eklampsia dan oligohidramnion. Bayi lahir langsung menangis dengan skor Apgar 8/9. Saat usia 3 menit bayi mengalami distres napas sehingga mendapatkan continuous positive airway pressure (CPAP) positive end expiratory pressure (PEEP) $7 \mathrm{FiO}_{2}$ $21 \%$. Pasien didiagnosis sepsis neonatus awitan dini dan mendapat terapi medikamentosa berupa antibiotik lini pertama (ampisilin dan gentamisin) dan nistatin yang diberikan secara oles pada mukosa mulut.

Saat usia 6 jam bayi mulai diberikan diet enteral menggunakan susu formula $10 \mathrm{ml} / \mathrm{kg} /$ hari. Diet dinaikkan secara bertahap $10 \mathrm{ml} / \mathrm{kg}$ dengan total kenaikan $30 \mathrm{ml} / \mathrm{kg} /$ hari. Saat usia 26 jam pasien mengalami apne pertama kali dan diberikan terapi aminofilin loading dose (LD) $6 \mathrm{mg} / \mathrm{kg}$ intravena (IV), kemudian dilanjutkan dengan maintenance dose (MD) $3 \mathrm{mg} / \mathrm{kg}$ setiap 12 jam IV. Pada usia 35 jam, distres napas membaik sehingga CPAP diturunkan menjadi PEEP $6 \mathrm{FiO}_{2} 21 \%$. Pada usia 3 hari distres napas membaik, terapi oksigen diturunkan menjadi high flow nasal (HFN) dengan aliran 5 liter per menit (lpm) dan $\mathrm{FiO}_{2} 21 \%$. Diet enteral mencapai $100 \mathrm{ml} /$ $\mathrm{kg} / \mathrm{hari}$ dan aminofilin diganti dengan kafein LD 20 $\mathrm{mg} / \mathrm{kg}$ per enteral dilanjutkan dengan kafein MD 6 mg setiap 24 jam.

Saat usia 7 hari pasien mengalami desaturasi, mottled, dan bradikardi disertai retraksi dinding dada sehingga diberikan CPAP PEEP $8 \mathrm{FiO}_{2} 21 \%$. Pasien dipuasakan dan kembali diberikan aminofilin rumatan IV. Pemeriksaan penanda infeksi mengalami perburukan sehingga antibiotik diganti dengan lini kedua (ampislin sulbaktam dan amikasin).

Saat usia 9 hari distres napas membaik, CPAP diturunkan bertahap kemudian diganti HFN 5 lpm, pasien mulai diet enteral dan aminofilin IV diganti kafein per enteral.

Saat usia 12 hari pasien mengalami takikardia kembali dengan laju nadi saat tidur $180 \mathrm{kali} /$ menit namun klinis dan laboratorium menunjukkan perbaikan infeksi. Pemeriksaan elektrokardiografi (EKG) menunjukkan sinus takikardia, ekokardiografi dan Rontgen toraks dalam batas normal. Pasien dianjurkan stop kafein, namun karena belum bebas apne selama 14 hari kafein tetap diberikan. 
Saat usia 19 hari usia koreksi 35 minggu pasien masih mengalami takikardia dengan laju nadi saat tidur sekitar 170-180 kali/menit, tidak ada klinis infeksi serta sudah lepas oksigen 5 hari sehingga kafein dihentikan.

Bayi usia gestasi 32 minggu dan berat lahir 1275 gram dengan AOP, diberikan terapi aminofilin dan dilanjutkan dengan kafein per enteral. Pada perawatan selanjutnya pasien mengalami perburukan klinis karena sepsis. Setelah infeksi membaik pasien masih mengalami takikardia. Kasus tersebut menimbulkan pertanyaan klinis sebagai berikut: bagaimana keamanan kafein dibandingkan dengan aminofilin sebagai terapi AOP ?

\section{Metode penelusuran}

Untuk menjawab masalah di atas, prosedur pencarian pustaka dilakukan dengan menelusuri literatur secara online, menggunakan instrumen pencari Pubmed, Cochrane, dan Highwire. Kata kunci yang digunakan adalah "methylxanthine", "neonate", "apne", "toxicity", "safety" dengan menggunakan batasan: bahasa pengantar adalah bahasa Inggris, publikasi dalam rentang waktu 10 tahun terakhir, serta penelitian dengan penelitian uji coba klinis, telaah sistematik atau meta analisis. Berdasarkan metode penelusuran dengan kriteria di atas, didapatkan 11 artikel, tetapi setelah ditelaah lebih lanjut terdapat 2 artikel yang dianggap relevan dengan masalah. Levels of evidence ditentukan berdasarkan klasifikasi yang dikeluarkan oleh Oxford Centre for Evidence-Based Medicine. ${ }^{6}$ Artikel yang terpilih adalah penelitian telaah sistematik dan uji klinis acak terkontrol.

\section{Hasil penelusuran}

\section{Telaah sistematis (Levels of evidence 1)}

Henderson $\mathrm{dkk}^{7}$ melakukan telaah sistematis pada tahun 2010 untuk membandingkan efektifitas dan keamanan kafein dan teofilin pada bayi prematur dengan apne berulang. Kriteria inklusi dalam telaah sistematis ini adalah uji acak terkontrol. Penelusuran dilakukan melalui MEDLINE (19662009), EMBASE (1990-2009), Oxford Database of Perinatal Trials, Cochrane Central Register of Controlled Trials, CENTRAL (2009). Luaran yang dinilai antara lain kejadian apne, angka rerata apne, penggunaan intermitten positive pressure ventilation (IPPV), efek samping dan tumbuh kembang. Data pada studi ini diambil dan diolah oleh 2 peninjau mandiri. Ditemukan 9 penelitian uji klinis, dan terdapat 5 studi yang memenuhi kriteria inklusi. Hasil telaah sistematis menunjukkan kejadian takikardia dan intoleransi minum lebih sedikit pada kelompok kafein dengan Relative Risk (RR) 0,17; $95 \%$ Interval kepercayaan (IK) 0,04, 0,72; risk difference $(\mathrm{RD})-0,29 ; 95 \%$ IK -0,47-0,10 . Terdapat 3 uji klinis pada telaah sistematis tersebut yang meneliti luaran toksisitas dan efek samping kafein dibandingkan teofilin yaitu penelitian oleh Bairam dkk, ${ }^{8}$ Scanlon dkk, ${ }^{9}$ dan Brouard dkk. ${ }^{10}$

II. Uji klinis acak terkontrol (Levels of evidence 2)

1. Bairam $\mathrm{dkk}^{8}$ melakukan uji klinis acak terkontrol pada 20 bayi prematur usia gestasi 30 minggu yang dibagi menjadi dua kelompok yaitu kelompok terapi teofilin yang mendapat teofilin loading dose (LD) 6 $\mathrm{mg} / \mathrm{kg}$ IV dilanjutkan dengan maintenance dose (MD) $2 \mathrm{mg} / \mathrm{kg}$ dua kali sehari IV dan kelompok kafein yang mendapat kafein LD $10 \mathrm{mg} / \mathrm{kg}$ dilanjutkan dengan MD 1,25 $\mathrm{mg} / \mathrm{kg}$ dua kali sehari IV. Hasil penelitian menunjukkan terdapat akselerasi frekuensi nadi setelah pemberian teofilin pada hari ke-1, $2,5,6$, dan $7(\mathrm{p}<0,05)$.

2. Scanlon $\mathrm{dkk}^{9}$ melakukan uji klinis acak terkontrol pada 40 bayi usia gestasi 31 minggu yang dibagi menjadi tiga kelompok yaitu kelompok terapi kafein dosis standar (a) dengan LD $25 \mathrm{mg} / \mathrm{kg} /$ hari IV drip selama 1,5 jam dilanjutkan MD $6 \mathrm{mg} / \mathrm{kg} / \mathrm{hari}$ IV drip selama 1,5 jam, kelompok terapi kafein dosis tinggi (b) dengan LD 50mg/kg IV drip 1,5 jam dan $12 \mathrm{mg} / \mathrm{kg}$ sekali sehari IV drip 1,5 jam dan kelompok teofilin (c) dengan LD $7,5 \mathrm{mg} / \mathrm{kg}$ IV continous infusion dilanjutkan dengan MD $3 \mathrm{mg} / \mathrm{kg}$ tiga kali sehari IV. Hasil penelitian menunjukkan 5 dari 12 bayi kelompok c membutuhkan penyesuaian dosis karena mengalami takikardia (laju nadi lebih dari $195 \mathrm{kali} /$ menit). Pemantauan efek samping selama 24 jam pada hari ke-5 terdapat peningkatan laju nadi sebesar $3 \mathrm{kali} /$ 
menit dan $5 \mathrm{kali} / \mathrm{menit}$ pada kelompok a dan $\mathrm{b}(\mathrm{p}<0,05)$ dan $12 \mathrm{kali} /$ menit pada kelompok c.

3. Brouard $\mathrm{dkk}^{10}$ melakukan uji klinis acak terhadap 16 bayi prematur dengan usia gestasi kurang dari 30 minggu. Subyek penelitian tersebut diikuti selama 2 tahun dan dibagi ke dalam dua kelompok perlakuan yaitu kelompok I yang mendapat aminofilin (theophylline ethylenediamine) LD $5,5 \mathrm{mg} / \mathrm{kg}$ IV dilanjutkan dengan dosis yang disesuaikan dengan target kadar plasma $5-10 \mathrm{mg} / \mathrm{L}$ dan kelompok II yang mendapat kafein LD 10 $\mathrm{mg} / \mathrm{kg}$ intamuskular (IM) dilanjutkan dengan MD 2,5 mg/kg sekali sehari per oral dengan target kadar plasma 8-16 mg/L. Penelitian tersebut menyimpulkan tidak terdapat perbedaan bermakna kejadian efek samping pada kedua kelompok sampai dengan hari ke5 , tetapi pada hari ke- 6 terdapat peningkatan laju nadi antara 165 sampai $210 \mathrm{kali} / \mathrm{menit}$ pada 1 bayi yang mendapat teofilin dengan dosis $0,9 \mathrm{mg} / \mathrm{kg}$ yang diberikan tiga kali sehari dengan konsentrasi plasma sebesar 21,6 mg/L.

4. Penelitian Skouroliakou dkk ${ }^{11}$ tahun 2009 melakukan uji klinis open label terkontrol non-plasebo pada bayi usia gestasi kurang dari 33 minggu yang bernapas spontan dan terindikasi pemberian metilxantin sebagai profilaksis atau terapi untuk AOP. Studi tersebut membandingkan teofilin/ aminofilin dengan kafein pada dosis standar sebagai terapi dan profilaksis AOP dalam menurunkan angka apne, menghubungkan konsentrasi obat di plasma dengan kejadian apne serta pemantauan pemberian obat. Penelitian ini membagi dua kelompok yaitu teofilin (I) dan kafein (II), dan masing-masing dibagi menjadi kelompok terapi (a) dan profilaksis (b). Standar dosis yang diberikan adalah aminofilin LD $6 \mathrm{mg} / \mathrm{kg}$ IV selama 30 menit dilanjutkan MD 2,5-3,5 mg/kg setiap 12 jam. Standar dosis kafein adalah LD 20 $\mathrm{mg} / \mathrm{kg}$ IV selama 30 menit dilanjutkan MD $5 \mathrm{mg} / \mathrm{kg}$ (sampai dengan $10 \mathrm{mg} / \mathrm{kg}$ ) sekali sehari diberikan selama 10 menit atau jika bayi sudah minum diberikan melalui orogastric tube (OGT). Terapi diberikan sampai bayi usia koreksi 34 minggu atau lebih pendek bila bayi dipindahkan ke rumah sakit (RS) lain. Kadar obat dalam darah dievaluasi 2 jam setelah LD dan 15 menit sebelum MD pada hari ke-3 dan ke-7 terapi dan setiap 7 hari kemudian. Selama intervensi dilakukan monitoring laju nadi, laju napas dan saturasi oksigen.

Sebanyak 37 bayi mendapat teofilin dan 33 bayi mendapat kafein. Kejadian apne meningkat signifikan pada kelompok yang mendapat profilaksis teofilin $(\mathrm{Ib}, \mathrm{p}=0,008)$ pada hari ke-1 sampai hari ke-3 dan hari ke-4 sampai hari ke-7 ( $\mathrm{p}=0,001)$, dengan kejadian apne lebih dari tiga kali per hari pada 6 pasien antara hari ke-1 sampai hari ke-3. Pada kelompok profilaksis kafein (IIb) kejadian apne tidak meningkat signifikan.

Pada kelompok terapi terdapat penurunan signifikan secara statistik dalam kejadian apne per hari setelah pemberian teofilin (Ia), pada hari ke-4 sampai hari ke-7 terapi $(\mathrm{p}=0,012)$. Kelompok terapi kafein (IIa) juga mengalami penurunan signifikan dalam kejadian apne sampai hari ke-4 sampai hari ke-7 terapi $(p=0,05)$. Saat keseluruhan data profilaksis dan terapi masing-masing teofilin dan kafein digabungkan, tidak ada penurunan angka apne per hari yang bermakna pada kelompok teofilin sebelum dan sesudah pemberian dan hingga 21 hari setelahnya. Pada kelompok kafein didapatkan penurunan bermakna angka apne per hari pada hari ke 1-3 dan 4-7 $(p=0,001$ dan $p=0,001)$. Konsentrasi plasma teofilin dan kafein juga stabil selama pemberian, dengan rentang yang lebih lebar pada kafein. Dosis teofilin diturunkan pada satu bayi yang konsentrasi plasmanya mencapai kadar $13,9 \mathrm{mg} / \mathrm{L}$ tanpa tanda-tanda toksisitas. Sebanyak 3 bayi mengalami iritabel, 2 bayi pada kelompok teofilin dan 1 bayi pada kelompok kafein. Tidak ada hubungan bermakna antara dosis pemberian kafein dan aminofilin pada konsentrasi plasma keduanya, kecuali pada kelompok kafein di hari ke-7. 


\section{Pembahasan}

Metilxantin telah menjadi pilihan pengobatan farmakologis AOP selama beberapa dekade. Pemberian kafein dibandingkan teofilin lebih disukai karena waktu paruh yang lebih panjang, indeks teurapeutik yang tinggi dan kurangnya kebutuhan dalam pemantauan kadar obat. Metilxantin memiliki beberapa efek pada respirasi termasuk peningkatan ventilasi semenit, peningkatan sensitivitas karbondioksida, menurunkan periodic breathing dan menurunkan depresi napas. ${ }^{12}$

Mekanisme utama metilxantin mengatasi apne melalui eksitasi respiratory neural ouput kemudian memblokade reseptor adenosin $A_{1}$ dan $A_{2 A}$ yang terletak pada neuron $\gamma$-aminobutyric acidergic. Reseptor adenosin dengan polimorfisme spesifik $A_{1}$ dan $A_{2 A}$ dikaitkan dengan tingginya risiko apne pada bayi prematur serta variasi respon terhadap metilxantin., ${ }^{2,12}$

Jenis metilxantin yang digunakan sampai saat ini yaitu kafein, aminofilin dan teofilin. Pilihan metilxantin yang digunakan berbeda-beda di beberapa negara, seperti di Thailand hanya $1 \%$ yang menggunakan kafein, sedangkan di Libanon, Australia dan Amerika Serikat mayoritas memilih kafein $(74 \%, 98 \%$ dan $96 \%$ ). Tidak ada data penggunaan aminofilin di Australia, tetapi di Thailand sebesar $88 \%$, Libanon 22 $\%$ dan di Amerika Serikat hanya $4 \%{ }^{13,17}$ Penelitian multisenter pada 1869 neonatus menunjukkan bahwa neonatus yang mendapat kafein memiliki biaya medis yang lebih murah secara keseluruhan dibandingkan neonatus yang mendapatkan plasebo. ${ }^{14}$

Efek samping metilxantin, yaitu takikardia, takipneu, jitteriness, tremor, iritabel, muntah, instabilitas gula darah, intoleransi minum. ${ }^{2}$ Tidak ditemukan dampak perkembangan kognitif dan perbedaan temperamen maupun perilaku pada bayi prematur yang mendapatkan kafein setelah pemantauan selama 1 tahun. ${ }^{15}$

Aminofilin memiliki kadar teurapeutik 4-8 mg/L dengan waktu paruh 24,7-36,5 jam dan estimasi bersihan $0,02-0,05 \mathrm{~L} / \mathrm{kg} / \mathrm{jam}$ pada bayi prematur. Berbeda dengan waktu paruh yang singkat pada aminofilin, kafein memiliki waktu paruh lebih lama sekitar 101 jam, oleh karena itu kafein dalam penggunaanya hanya diberikan satu kali sehari. Pada usia gestasi 34-36 minggu biasanya AOP menghilang tetapi pada neonatus yang lebih imatur AOP dapat terjadi hingga usia koreksi 43-44 minggu. ${ }^{2,16}$
Penelitian yang meneliti luaran toksisitas metilxantin terutama golongan aminofilin dalam beberapa dekade sangat sedikit karena kecenderungan kafein lebih dipilih sebagai terapi AOP. Penelitian oleh Henderson $\mathrm{dkk}^{7}$ membandingkan efektivitas kafein dan teofilin dengan hasil kejadian takikardia dan intoleransi minum lebih sedikit pada kelompok kafein. Teofilin dan kafein memiliki efektivitas yang sama dalam menurunkan angka apne pada bayi prematur. Penelitian oleh Skroliaokou $\mathrm{dkk}^{11}$ membandingkan aminofilin dengan kafein dengan hasil efek toksik lebih sedikit pada kelompok kafein.

Kasus bayi usia gestasi 32 minggu dan berat lahir 1275 gram dengan apne prematuritas diberikan aminofilin dan dilanjutkan dengan kafein. Pada perawatan selanjutnya pasien mengalami perburukan klinis karena sepsis. Setelah infeksi membaik pasien masih mengalami takikardia setelah bebas kafein selama tiga hari. Terdapat dua penelitian yang relevan untuk menjawab pertanyaan klinis mengenai efek toksisitas kafein dibandingkan dengan aminofilin sebagai terapi pada AOP. Tidak ada satu pun penelitian menunjukkan hasil yang signifikan mengenai toksisitas kafein lebih banyak daripada aminofilin. Penelitian oleh Handerson $\mathrm{dkk}^{7}$ menunjukkan bahwa efek samping takikardia dan intoleransi minum lebih sedikit pada kelompok kafein. Penelitian Skouroliakou dkk ${ }^{11}$ juga menunjukkan tidak terdapat tanda-tanda toksisitas pada kedua terapi dengan dosis standar.

\section{Kesimpulan}

Aminofilin dan kafein memiliki efektivitas yang sama dalam mengatasi apne pada bayi prematur. Berdasarkan penelitian ilmiah yang telah dipaparkan kafein memiliki efek toksik lebih sedikit dibandingkan aminofilin. Efek samping kafein sebagaimana metilxantin pada umumnya masih dapat ditemukan pada bayi prematur namun tidak terbukti bahwa efek samping kafein lebih tinggi dibandingkan dengan aminofilin.

\section{Saran}

Kafein lebih disukai karena waktu paruh yang lebih panjang dan efek toksisitas yang lebih rendah sehingga pengadaannya dalam sediaan intravena di RS tipe A seperti RSCM perlu dipertimbangkan. 


\section{Daftar pustaka}

1. Sari S, Tjipta GD, Aldy D. Pengguan metilxantin pada bayi prematur dengan apne idiopatik. Sari Pediatri 2004;6:129-33.

2. Schoen K, Yu T, Stockmann C, Spigarelli MG, Sherwin CM. Use of methylxanthine therapies for the treatment and prevention of apnea of prematurity. Paediatr Drugs 2014;16:169-77.

3. Theobald K, Botwinski C, Albanna S, McWilliam P. Apnea of prematurity: diagnosis, implications for care, and pharmacologic management. Neonatal Netw 2000;19:17-24.

4. Montandon G, Bairam A, Kinkead R. Long-term consequences of neonatal caffeine on ventilation, occurrence of apnes, and hypercapnic chemoreflex in male and female rats. Pediatr Res 2006;59:519-24.

5. Natarajan G, Lulic-Botica M, Aranda JV. Pharmacologic review: clinical pharmacology of caffeine in the newborn. Neoreviews 2007;8:e214-21.

6. Oxford Centre of Evidence-Based Medicine 2011 Levels of Evidence [diakses 15 Juni 2016]. Didapat dari: http:// www.cebm.net/wp-content/uploads/2014/06/CEBMLevels-of-Evidence-2.1.pdf2011

7. Henderson-Smart DJ, Steer PA. Caffeine versus theophylline for apne in preterm infants. Cochrane Database Syst Rev [internet]. 2010 [disitasi 4 Juni 2016]. Didapat dari: http://onlinelibrary.wiley.com/ doi/10.1002/14651858.CD000273.pub2/pdf

8. Bairam A, Boutroy MJ, Badonnel Y, Vert P. Theophylline versus caffeine: comparative effects in treatment of idiopathic apne in the preterm infant. J Pediatr 1987;110:636-9.
9. Scanlon JE, Chin KC, Morgan ME, Durbin GM, Hale KA, Brown SS. Caffeine or theophylline for neonatal apnoea? Arch Dis Child 1992;67:425-8.

10. Brouard C, Moriette G, Murat I, Flouvat B, Pajot M, Waiti H, dkk. Comparative efficacy of theophylline and caffeine in the treatment of idiopathic apne in premature infants. Am J Dis Child 1985;139:698-700.

11. Skouroliakou M, Bacopoulou F, Markantonis SL. Caffeine versus theophylline for apnea of prematurity: a randomised controlled trial. J Paediatr Child Health 2009;45:587-92.

12. Eichenwald EC. Apnea of prematurity. Pediatrics 2016;137:1-8.

13. Abu Jawdeh EG, O'Riordan M, Limrungsingkul A, Bandyopadhyay A, Argus BM, Nakad PE, dkk. Methylxanthine use for apnea of prematurity among an international cohort of neonatologist. J Neonatal Perinatal Med 2013;103;251-6.

14. Dukhovny D, Lorch SA, Schmidt B, Doyle LW, Kok $\mathrm{JH}$, Roberts RS, dkk. Economic evaluation of caffeine for apnea of prematurity. Pediatrics 2011;127:e146-55.

15. Gray PH, Flenady VJ, Charles BG, Steer PA. Caffeine citrate for very preterm infants: effects on development, temperament and behaviour. J Paediatr Child Health 2011;47:167-72.

16. Schmidt B, Roberts RS, Davis P, Doyle LW, Barrington KJ, Ohlsson A, dkk. Caffeine therapy for apnea of prematurity. N Engl J Med 2006;354:2112-21.

17. Dobson NR, Patel RM, Smith PB, Kuehn DR, Clark J, Vyas-Read S, dkk. Trends in caffeine use and association between clinical outcomes and timing of therapy in very low birth weight infants. J Pediatr 2014;164:992-98. 